\title{
Transient neonatal diabetes mellitus
}

INSERM

\section{Source}

INSERM. (1999). Orphanet: an online rare disease and orphan drug data base. Transient neonatal diabetes mellitus. ORPHA:99886

Transient neonatal diabetes mellitus (TNDM) is a genetically heterogeneous form of neonatal diabetes (NDM, see this term) characterized by hyperglycemia presenting in the neonatal period that remits during infancy but recurs in later life in most patients. 